Marine Genomics

June 2014, Volume 15 Pages 3-4

https://doi.org/10.1016/j.margen.2014.03.006

https://archimer.ifremer.fr/doc/00202/31362/

\title{
Deep sequencing of the mantle transcriptome of the great scallop Pecten maximus
}

Artigaud Sébastien ${ }^{1,}{ }^{*}$, Thorne Michael A. S. ${ }^{2}$, Richard Joëlle ${ }^{1}$, Lavaud Romain ${ }^{1}$, Jean Fred ${ }^{1}$, Flye-Sainte-Marie Jonathan ${ }^{1}$, Peck Lloyd S. ${ }^{2}$, Pichereau Vianney ${ }^{1}$, Clark Melody S. ${ }^{2}$

${ }^{1}$ Univ Bretagne Occidentale, Inst Univ Europeen Mer, LEMAR UMR CNRS UBO IRD Ifremer 6539, Lab Sci Environm Marin, F-29280 Plouzane, France.

${ }^{2}$ British Antarctic Survey, Nat Environm Res Council, Cambridge CB3 0ET, England.

*Corresponding author : Sébastien Artigaud, email address : sebastien.artigaud@gmx.com

\begin{abstract}
:
RNA-Seq transcriptome data were generated from mantle tissue of the great scallop, Pecten maximus. The consensus data were produced from a time course series of animals subjected to a 56-day thermal challenge at 3 different temperatures. A total of 26,064 contigs were assembled de novo, providing a useful resource for both the aquaculture community and researchers with an interest in mollusc shell production.
\end{abstract}

Keywords : Pecten maximus, RNAseq, Temperature 


\section{Introduction}

The great scallop Pecten maximus is a bivalve mollusc, which occurs over a wide latitudinal gradient, from Spain to Norway, inhabiting depths from $0 \mathrm{~m}$ to $500 \mathrm{~m}$ (Chauvaud et al., 2005). This is an economically important species, comprising almost $80 \%$ of European wild harvested scallops. Furthermore, aquaculture is expanding, especially in France and Ireland where hatcheryproduced seed is used to enhance the production in the wild. The transcriptome data were generated as part of a more detailed study, investigating the effect of temperature on growth and development. 
One year old scallops (average length : $34.0+/-4.1 \mathrm{~mm}$ ) were obtained from the Tinduff hatchery (Bay of Brest, France). They were cultured at 3 different temperatures: ambient controls at $14.8 \pm 0.6^{\circ} \mathrm{C}$ and also the elevated temperatures of $21.4 \pm 0.2^{\circ} \mathrm{C}$ and $25.2 \pm 0.9^{\circ} \mathrm{C}$. Individuals in each treatment were sampled over a time course from the beginning of the experiment and then after 3, 7, 14, 21, 27, 42 and 56 days. The scallops were dissected and mantle tissue was flash frozen in liquid nitrogen and stored at $-80^{\circ} \mathrm{C}$ until further analysis. Total RNA was extracted from mantle tissue of 4 individuals per treatment at each time point using TRI Reagent ${ }^{\circ}$ Solution (Life Technologies) according to manufacturer's instructions. RNA quality and concentration were determined using an Agilent 2100 RNA Nanochip (Agilent, Santa Clara, CA, USA) and a NanoDrop ND-1000 Spectrophotometer (NanoDrop Technologies, Wilmington, DE, USA), respectively. For each condition, the RNAs from the 4 individuals at each time point were then pooled for RNA-Seq. From these pooled samples, 22 cDNA libraries were produced (cf. Table 1 for details). The production of the Illumina libraries and the transcriptome sequencing using the Illumina HiSeq ${ }^{\mathrm{TM}} 2500$ (HiSeq $100 \mathrm{bp}$ pair-ends) was conducted by the Genome Analysis Centre (Norwich, UK).

Table 1 : Sampling details for the 22 cDNA libraries produced from mantle tissue of Pecten maximus

\begin{tabular}{llll} 
library name & Illumina pair reads & Days of sampling & Water temperature \\
\hline LIB650 & 84501929 & 0 & 15.21 \\
LIB1034 & 28360963 & 3 & 14.75 \\
LIB530 & 33666167 & 3 & 19.47 \\
LIB651 & 36249865 & 3 & 19.23 \\
LIB531 & 31338366 & 7 & 21.46 \\
LIB532 & 23236209 & 7 & 14.8 \\
LIB533 & 41914200 & 7 & 21.4 \\
LIB1035 & 29169807 & 14 & 24.98 \\
LIB1036 & 23746508 & 14 & 14.94 \\
LIB1037 & 31458013 & 14 & 21.53 \\
LIB654 & 30034307 & 21 & 25.36 \\
LIB655 & 20315515 & 21 & 14.69 \\
LIB660 & 28367527 & 21 & 21.37 \\
LIB656 & 14723720 & 27 & 25.33 \\
LIB657 & 22531517 & 27 & 21.44 \\
LIB661 & 29224707 & 27 & 14.88 \\
LIB658 & 29214964 & 42 & 14.86 \\
LIB662 & 26693489 & 42 & 25.35 \\
LIB663 & 32078459 & 42 & 21.48 \\
LIB1038 & 15276016 & 56 & 25.37 \\
LIB664 & 28606041 & 56 & 14.78 \\
LIB665 & 26853248 & 56 & 21.49
\end{tabular}


The RNA libraries yielded 667 million paired end reads. Raw reads were filtered and trimmed using the FASTX-toolkit (Version 0.0.13 from Assaf Gordon Hannon lab) and rRNA contamination was removed using riboPicker (Schmieder et al., 2012) and cutadapt (Version 1.1; Martin, 2011), with a final quality check $\begin{array}{lllll}\text { performed using } & \text { fastQC } & \text { (Version } & 0.10 .0 \text {; }\end{array}$ http://www.bioinformatics.bbsrc.ac.uk/projects/fastqc/).

The contigs were assembled using SOAPdenovo (Luo et al., 2012), and a kmer size of 89 was used to construct the initial de novo transcriptome assembly, resulting in 1,311,367 contigs. These contigs were then used in a further assembly with CAP3 (Huang \& Madan, 1999). Contigs from both rounds of assemblies that were greater than $500 \mathrm{bp}$, totaling 26064 , were used in a sequence similarity search against an in-house $\mathrm{nr}$ database using an e-value cutoff of 1e-10. Putative annotation based on sequence similarity searching could be assigned to approximately $23.5 \%$ of the contigs (Table 2 ).

Table 2 : Statistics for the transcriptome generation from mantle tissue of Pecten maximus

\begin{tabular}{|l|l|}
\hline Total reads & 1335123074 \\
\hline Total Contigs & 26064 \\
\hline Average Contig length (bp) & 1011 \\
\hline Median length (bp) & 815 \\
\hline Max length (bp) & 11760 \\
\hline Min length (bp) & 490 \\
\hline$\%$ Annotated Contigs & $23.5 \%$ \\
\hline
\end{tabular}

These data generated from the mantle of $P$. maximus form a valuable addition to those generated from hemocytes of the same species (Pauletto et al., 2014) and, in a more general context, to the transcriptomes generated for other molluscs including the Yesso scallop Patinopecten yessoensis (Hou et al., 2011), Mytilus galloprovincialis (Craft et al., 2010), Laternula elliptica (Clark et al., 2010), Meretrix meretrix (Huan et al., 2012), Ruditapes philippinarum (Milan et al., 2011), Haliotis midae (Franchini et al., 2011), several pearl oysters (Huang et al., 2013) and the oyster genome data (Zhang et al., 2012), thus increasing the sequence resource available for commercially important shellfish species and for researchers investigating shell deposition processes in molluscs.

\section{Nucleotide sequence accession numbers}

The sequence data for this transcriptome has been deposited in the GenBank SRA, accession number: SRP040427. The contigs, and the annotation for those contigs with a match of $1 \mathrm{e}-10$ and lower, are available from http://ramadda.nercbas.ac.uk/repository/entry/show/Polar+Data+Centre/NERC-BAS+Datasets/Genomics/ 


\section{Acknowledgements}

This study was funded by grants from the Région Bretagne, i.e. the Pemadapt project (ref. 6368) and a doctoral fellowship to S.A. (Protmar project, ref. 6197). This study was also supported by a Natural Environment Research Council (NERC) grant to Lloyd Peck (NE/G018) and the British Antarctic Survey Polar Sciences for Planet Earth programme, which is also funded by the Natural Environment Research Council. Two French National Research Agency (ANR) programs also supported our research: COMANCHE (ANR-2010-STRA-010) and LabexMER (ANR-10-LABX-19-01).

\section{REFERENCES}

Chauvaud, L., Lorrain, A., Dunbar, R.B., Paulet, Y., Thouzeau, G., Jean, F., Guarini, J. \& Mucciarone, D. (2005) "Shell of the Great Scallop Pecten maximus as a high-frequency archive of paleoenvironmental changes." Geochemistry, Geophysics, Geosystems, 6, Q08001.

Clark, M.S., Thorne, M.A.S., Vieira, F.A., Cardoso, J.C.R., Power, D.M. \& Peck, L.S. (2010) "Insights into shell deposition in the Antarctic bivalve Laternula elliptica: gene discovery in the mantle transcriptome using 454 pyrosequencing." Bmc Genomics, 11, 362.

Craft, J.A., Gilbert, J.A., Temperton, B., Dempsey, K.E., Ashelford, K., Tiwari, B., Hutchinson, T.H. \& Chipman, J.K. (2010) "Pyrosequencing of Mytilus galloprovincialis cDNAs: tissue-specific expression patterns." PLoS one, 5, e8875.

Franchini, P., Van der Merwe, M. \& Roodt-Wilding, R. (2011) “Transcriptome characterization of the South African abalone Haliotis midae using sequencing-by-synthesis." BMC research notes, 4, 59.

Hou, R., Bao, Z., Wang, S., Su, H., Li, Y., Du, H., Hu, J., Wang, S. \& Hu, X. (2011) "Transcriptome sequencing and de novo analysis for Yesso scallop (Patinopecten yessoensis) using 454 GS FLX." PloS one, 6, e21560.

Huan, P., Wang, H. \& Liu, B. (2012) "Transcriptomic analysis of the clam Meretrix meretrix on different larval stages." Marine Biotechnology, 14, 69-78.

Huang, X. \& Madan, A. (1999) “CAP3: A DNA sequence assembly program.” Genome research, 9, 868-877.

Huang, X.-D., Zhao, M., Liu, W.-G., Guan, Y.-Y., Shi, Y., Wang, Q., Wu, S.-Z. \& He, M.X. (2013) “Gigabase-Scale Transcriptome Analysis on Four Species of Pearl Oysters." Marine Biotechnology, 15, 253-264. 
Luo, R., Liu, B., Xie, Y., Li, Z., Huang, W., Yuan, J., He, G., Chen, Y., Pan, Q., Liu, Y., Tang, J., Wu, G., Zhang, H., Shi, Y., Liu, Y., Yu, C., Wang, B., Lu, Y., Han, C., Cheung, D.W., Yiu, S.-M., Peng, S., Xiaoqian, Z., Liu, G., Liao, X., Li, Y., Yang, H., Wang, J., Lam, T.-W. \& Wang, J. (2012) "SOAPdenovo2: an empirically improved memory-efficient short-read de novo assembler." GigaScience, 1, 18.

Martin, M. (2011) “Cutadapt removes adapter sequences from high-throughput sequencing reads." EMBnet.journal, 17, 10-12.

Milan, M., Coppe, A., Reinhardt, R., Cancela, L.M., Leite, R.B., Saavedra, C., Ciofi, C., Chelazzi, G., Patarnello, T., Bortoluzzi, S. \& Bargelloni, L. (2011)

"Transcriptome sequencing and microarray development for the Manila clam, Ruditapes philippinarum: genomic tools for environmental monitoring." BMC genomics, 12, 234.

Pauletto, M., Milan, M., Moreira, R., Novoa, B., Figueras, A., Babbucci, M., Patarnello, T. \& Bargelloni, L. (2014) "Deep transcriptome sequencing of Pecten maximus hemocytes: A genomic resource for bivalve immunology." Fish \& Shellfish Immunology, 37, 154-165.

Schmieder, R., Lim, Y.W. \& Edwards, R. (2012) "Identification and removal of ribosomal RNA sequences from metatranscriptomes." Bioinformatics, 28, 433-435.

Zhang, G., Fang, X., Guo, X., Li, L., Luo, R., Xu, F., Yang, P., Zhang, L., Wang, X., Qi, H., Xiong, Z., Que, H., Xie, Y., Holland, P.W.H., Paps, J., Zhu, Y., Wu, F., Chen, Y., Wang, J., Peng, C., Meng, J., Yang, L., Liu, J., Wen, B., Zhang, N., Huang, Z., Zhu, Q., Feng, Y., Mount, A., Hedgecock, D., Xu, Z., Liu, Y., Domazet-Lošo, T., Du, Y., Sun, X., Zhang, S., Liu, B., Cheng, P., Jiang, X., Li, J., Fan, D., Wang, W., Fu, W., Wang, T., Wang, B., Zhang, J., Peng, Z., Li, Y., Li, N., Wang, J., Chen, M., He, Y., Tan, F., Song, X., Zheng, Q., Huang, R., Yang, H., Du, X., Chen, L., Yang, M., Gaffney, P.M., Wang, S., Luo, L., She, Z., Ming, Y., Huang, W., Zhang, S., Huang, B., Zhang, Y., Qu, T., Ni, P., Miao, G., Wang, J., Wang, Q., Steinberg, C.E.W., Wang, H., Li, N., Qian, L., Zhang, G., Li, Y., Yang, H., Liu, X., Wang, J., Yin, Y. \& Wang, J. (2012) "The oyster genome reveals stress adaptation and complexity of shell formation." Nature, 490, 49-54. 